\title{
Using numbers that do not count: how the latent functions of performance indicators explain their
} success

\author{
Shirley Kempeneer \\ University of Antwerp, Belgium \\ Wouter Van Dooren \\ University of Antwerp, Belgium \\ International Review of Administrative Sciences \\ DOI: $10.1177 / 0020852319857804$ journals.sagepub.com/home/ras
}

\begin{abstract}
Performance indicators have had to endure severe criticism. They are said to lack accuracy, encourage gaming and ultimately fail to improve performance. Yet, despite their well-documented weaknesses, performance indicators abound in governance. This article asks under which conditions performance indicators can improve performance outcomes, despite these proven weaknesses and dysfunctions. Our case study is the stress test of the European banking system, a high-profile performance indicator used for risk regulation. Based on interviews with risk managers in Belgian banks as well as staff at the European Central Bank, the European Banking Authority and the National Bank of Belgium, we find that the process of calculating the stress test improves performance outcomes in itself. It does so by fostering banks' capacity to self-regulate, tying into Foucault's notion of governmentality. As such, practitioners and academics should not only pay attention to how performance results can be used, but also examine how the process of calculating the performance indicator might be designed to improve performance outcomes latently.
\end{abstract}

Keywords

Banking stress test, governmentality, performance indicators, performance measurement

Corresponding author:

Shirley Kempeneer, University of Antwerp, Sint-Jacobstraat 2, Antwerpen 2000, Belgium.

Email: shirley.kempeneer@uantwerpen.be 


\section{Introduction}

Since the global financial crisis, stress testing has become part and parcel of reg-ulators' toolkits for monitoring and maintaining financial stability globally. In Europe, the European Banking Authority (EBA), in close coordination with the European Central Bank (ECB), now conducts system-wide stress tests to simulate the ability of the big, socalled systemic, banks to deal with an adverse scenario, making it easy to rank banks from worst to best 'performer'.

At first sight, the success of stress tests is easy to explain. As awareness for risks increases, the demand for instruments that measure and control risks is growing (Power, 1997). Performance indicators' success hinges on their ability to simplify, standardise, compare and control complex systems. The European Union (EU)-wide stress test delivers on this demand for control. The stress tests are designed to show at a glance the banks that would weather a crisis.

However, decades of research have also exposed the adverse effects of perfor-mance indicators. They are said to lack accuracy, encourage gaming, demotivate workers, be biased towards what is quantifiable and ultimately fail to substantially improve performances (Berten and Leisering, 2017; Bevan and Hood, 2006; Bouckaert and Balk, 1991; Davis et al., 2012; Pollitt, 2018). Research has also identified the misuse of performance information as a key factor hampering per-formance improvement (Taylor, 2011; Van Dooren et al., 2015). Some scholars go so far as to claim that 'evidence-based' and 'rational' policymaking is a myth because policy work is fundamentally political (Boswell, 2015). Adverse effects are primarily at play when highly incentivised performance indicators are used (Bevan and Hood, 2006). The stress tests have not been spared this criticism, especially in financial media. Stress tests are said to not make sense economically, be biased towards certain banks and be little more than communication exercises to reassure financial markets (Cecchetti and Schoenholtz, 2016; Dowd, 2015; Elliott, 2016).

To be sure, there are studies that show how performance measurement posi-tively affects performance outcomes (Boyne and Chen, 2006; Nielsen, 2014; Walker et al., 2011). Yet, we do not have a clear understanding of why perfor-mance indicators improve performance outcomes in some cases and fail to do so in others.

Despite these differing and seemingly contradictory effects of performance indi-cators, regulators continue to promote them as indispensable tools for regulation. Over the past decades, the use of performance indicators has proliferated in (global) governance (Davis et al., 2012). The ambition of this article is thus to explain the enduring success of performance indicators, and explore under which conditions they can improve performance outcomes, despite their proven weak-nesses and dysfunctions.

We find that performance indicators have important latent functions that have so far been under-studied in the literature. We borrow the concept of a latent function from Merton's (1968) functional sociology. Merton distinguishes between 
manifest functions (intended and positive effects), dysfunctions (unintended and negative effects) and latent functions (unintended positive effects). The perfor-mance literature typically deals with the manifest functions and dysfunctions of performance information. In this article, we take a closer look at the latent functions.

Our case study studies the latent functions of the stress test. First of all, we show that the process of calculating the stress test latently improves performance out-comes. To complete the stress test in a timely fashion, banks have professionalised their internal riskmanagement systems, investing in enhanced data quality, improved information technology (IT) systems and better coordination between risk domains. This inadvertently improves their performance outcomes. Second, we find that previously recognised latent functions, such as the ritualistic and symbolic function of performance indicators (Boswell, 2015; Power, 1997), are much more important for performance outcomes than they are often ascribed to be. Finally, we find that certain dysfunctions, such as the inaccuracy of results, do not necessarily hamper performance outcomes.

\section{Manifest functions of performance indicators}

Indicators abound in public governance. New Public Management (NPM) reforms in particular have led to the dissemination of indicators in all corners of govern-ment (Van Dooren et al., 2015). NPM aggregates a plethora of policy principles that all in some way intend to improve public sector performance by making it more efficient and goal-centred (Van Dooren et al., 2015). It does so through the principles of disaggregation, competition and incentivisation (Dunleavy et al., 2005). For performance-based regulation to work, a key condition is that perfor-mance needs to be measured, and this is where performance indicators enter the picture. Many of the incentives that NPM promotes can only be applied when quantitative performance indicators are available.

Performance indicators easily found their way to the regulators' toolbox as they provide information at a glance. They provide an objective measure of which organisations are reaching targets and who is underperforming. This information can then be used to improve performance outcomes by fostering competition between organisations, allocating resources according to performance and increas-ing accountability (Braithwaite, 2014; Kagan, 1995; Levi-Faur, 2005). Moreover, the simplicity of performance indicators allows for more succinct communication with actors inside and outside government, tapping into an agenda of transparency and accountability, at least in theory (Sarfaty, 2011).

\section{Dysfunctions of performance indicators}

Despite the aforementioned noble intentions, and high hopes, an increasing number of critical voices cite the paradoxical and dysfunctional effects of NPM and performance indicators, calling for a post-NPM reform (Christensen and 
Fan, 2016; Klenk and Reiter, 2019; Mikuła and Kaczmarek, 2019; Reiter and Klenk, 2018). After more than three decades of performance measurement in public policy, even sympathetic analysts like Hood and Peters (2004) or Dunleavy et al. (2005) acknowledge the adverse effect of NPM reforms, especially performance indicators (Pires, 2011). Although in some (predominantly develop-ing) countries, NPM reforms are still playing out, most advanced countries have come to realise that NPM has not fostered more effective or efficient public organ-isations. Instead, the NPM themes of disaggregation, competition and incentivisa-tion led to siloed public bodies impeding collective action, perverse quasi-market mechanisms and an obsession with intermediate organisational targets oversha-dowing service delivery and effectiveness (Dunleavy et al., 2005). In line with this, performance indicators specifically received a number of criticisms as well.

A first dysfunctional effect is that performance indicators may lead to tunnel vision. They tend to focus upon easily quantified dimensions of performance, thereby narrowing down the focus of policymaking and political debate to a small and often unrepresentative aspect of policy (Bevan and Hood, 2006; Pidd, 2005; Power, 1997; Termeer et al., 2013). Doig, McIvor and Theobald (2006) add to this that an overreliance on scores and rankings might overlook the fact that the phenomena they intend to depict are moving targets in terms of progress and direction. In the stress test, easily quantifiable risk areas such as credit and market risks have been addressed substantially, while areas that are more difficult to quantify, and difficult to pin down and define, such as operational risk, are less developed.

Besides this, performance indicators can create perverse incentives and encour-age 'gaming' and cheating. There are many empirical examples of how data are manipulated (Bevan and Hood, 2006; Hood and Peters, 2004; Pollitt and Talbot, 2004; Smith, 1995; Stone, 2002). For instance, hospitals will cancel appointments or schedule fewer follow-up meetings to cut down waiting lists, creating an illusion of efficiency. Indicators are also said to stifle curiosity and diminish learning opportunities (Radin, 2006). Moreover, performance indicators may lead to goal displacement, where organisations focus on the indicators rather than the under-lying objective that the indicators are supposed to measure (Bohte and Meier, 2000). Furthermore, as O’Neill (2002) and Power (1997) have shown in their work on audits, performance indicators often obscure what is actually happening in the workplace, fuelling suspicion and mistrust, undermining professional ethics, and generating a host of unforeseen problems.

Finally, the information that performance indicators produce is often not even used or applied in decision-making (Johnston, 2004; Mol and De Kruijf, 2004; Pollitt and Talbot, 2004; Taylor, 2011; Walshe et al., 2010). Frequent causes are the insufficient quality of the performance information and the lack of important data, but also cultural or institutional barriers (Hoogenboezem, 2004; Van Dooren et al., 2015). De Vries (2010) adds that performance measures are usually a-contextual and unable to reveal anything substantive about the quality of 
politics. Performance indicators are just more red tape and paperwork, wasting away in binders and computer folders.

This leaves us with a puzzle: with so many dysfunctions from research and practice being documented, under which circumstances can performance indicators actually improve performance outcomes? We claim that the answer is to be found in the latent functions of performance indicators.

\section{Methodology}

We aim to explain under which conditions performance indicators, such as the stress test, can improve performance outcomes, despite their proven weaknesses and dysfunctions. We operationalise this by studying the contribution of the stress test to risk performance according to regulators (the National Bank of Belgium (NBB), the ECB and the EBA), regulatees (the Belgian banks) and intermediate organisations (consultancy firms). We aim to understand how these actors make sense of and give meaning to the stress test as a tool of governance. We selected the EU-wide banking stress test because it is an eminent example of a performance indicator that has placed itself at the centre of risk regulation in the wake of the 2008 financial crisis. Moreover, it is a fairly recent indicator (only a decade old) and, as such, its design is still subject to yearly changes. We are interested in how the stress test has developed over time and how the different iterations of the stress test have affected performance outcomes, according to those involved.

We conducted 45 conversational interviews with 33 people. The interviews lasted 75 minutes on average. We did a first round of 18 interviews in Belgian banks and four in consulting firms in 2015/2016; a second round of eight interviews was done at the ECB in 2017; and in a third round, we conducted nine interviews in banks, one in a consulting firm, three at the EBA and two at the NBB. We selected the four Belgian banks that were involved in the stress test and contacted the Chief Risk Officer. Then, we used the snowball method to assess which other key people in the bank were involved in the stress test, and planned interviews with them. We selected our respondents at the ECB, EBA and NBB through desk research. We also attended two seminars on stress testing, ${ }^{1}$ where we were able to speak to people (new as well as previously interviewed respondents ${ }^{2}$ ) in a more informal setting. We continued interviewing until we had gathered sufficient information to formulate an answer to our research question.

We transcribed the interviews verbatim, and used 'Nvivo' software to code and analyse the data systematically. We took an interpretive approach to our analysis (Schwartz-Shea and Yanow, 2012; Yanow and Schwartz-Shea, 2006). This means that we focused on how respondents made sense of the exercise and the perfor-mance outcomes. Our research strategy also follows an abductive logic (Timmermans and Tavory, 2012). This means that we started from an empirical finding and then went back and forth between our research field and theory. Our results section reflects this abductive logic. Empirical findings and theoretical implications are not separated, but alternate in the text. We used a semistructured 
topic guide during all interviews. After each round of coding, we revisited our topic guide and added new theoretical concepts to go back into the field. Our topic guide allowed us to discuss the same set of topics with all respondents and still act in a responsive way.

In order to stay close to the experience of the respondents, we first used emer-gent codes, close to the text, to code interview transcripts (Drisko and Maschi, 2015). Our goal was to study how the stress test affected performance outcomes. Subsequent rounds of coding therefore focused on identifying how various ele-ments of the stress test affected organisational behaviour and how the stress test was experienced by the various respondents. The resulting coding process clearly showed links between the latent functions of the stress test and changes in banks' behaviour. Based on this analysis, we gained an overview of how the stress test affected performance outcomes, which is presented in the following.

\section{The latent functions of the EU-wide stress test}

Our interviews gave us three key understandings of how performance indicators affect performance outcomes. We present our findings and theoretical interpreta-tion simultaneously so as to allow the reader to follow our abductive analytical process. First, we show how a common dysfunction of performance indicators - inaccurate measurement - does not hamper performance outcomes. Second, we corroborate and complement the existing literature on the latent ritualistic functions of indicators, showing that these can importantly affect performance outcomes. Finally, we show how the process of calculating the performance indi-cator can have a larger impact on performance outcomes than (the use of) the performance information itself. In calculating the stress test, banks made internal changes that improved long-term performance outcomes.

\section{The numbers are not right}

A common dysfunction addressed earlier in this article is that, ultimately, perfor-mance indicators do not provide accurate performance information. Results are often said to be inaccurate, biased or gamed. In this section, we examine how the actors involved perceive and deal with this apparent dysfunction.

Banks have unique assets in their portfolio that justify a unique way to calculate the risk weight of those assets. However, when given too much freedom, banks would end up with different risk weights even for very similar assets, gaming the system to their advantage. As such, the stress-test methodology introduced caps and floors to somewhat level out the differences between banks' internal models. However, this common methodology was said to stand in the way of accurately reflecting banks' individual risk, raising questions about using the stress test to assess banks' performance. When we mentioned the EBA's common methodology to stress-testing teams, respondents sighed and started to shake their heads. A lot of bottled-up frustrations flowed freely, as a respondent noted: 'What you see in 
the EBA stress test is that you are put in a corset in terms of methodology. This is necessary to be able to compare banks, but it does not make sense economically.' Although the stress test makes a good effort at treating banks' risks and assets equally through the common methodology, the exercise sometimes lumps very different things together at the cost of accuracy. This supports the critical voices. The stress test might not paint a very accurate picture of each bank's actual performance, which might lead to unjust performance evaluation.

However, some nuance is required here. A goal of the European stress test was to do away with national bias and establish a European Level Playing Field (LPF). Although the stress test compromises on accuracy, without the LPF, the stress test would, most likely, not be taken seriously at all. As many respondents pointed out, the early $(2009,2010)$ stress tests - where the common methodology was only a few pages long - gave banks substantial discretion in their calculations, which was often used to game results to banks' advantage. While the stress-testing exercise today is frustrating to banks (which are concerned above all with having an accu-rate result for their bank), all respondents agreed that, overall, the results paint a fairer picture of banks' performance vis-a-vis each other. As such, we find that both regulators and regulatees agree that the stress test is dysfunctional, in the sense that it does not provide a completely accurate calculation of banks' perfor-mance under risk, but it does minimise gaming, which leads to an overall better assessment of banks' performance.

\title{
Rituals of verification
}

Although risk teams in banks were sympathetic towards the detailed rulebook and the LPF, they remained particularly frustrated about the granularity and intensity of the exercise. A respondent in a bank commented somewhat jokingly:

\begin{abstract}
Risks are very specific, your clients can be pharmacists, and pharmacists are not butchers, it's a specific market, so the model needs to be specific. People with car loans in [one region], that's different from loans in [another region]. And each model depends on the behaviour of your clients, so you need behavioural parameters. That's what the internal models are for. And then what does the ECB do? They just add a buffer. But it's the same everywhere I guess. Engineers do this too, they make com-plicated calculations about how much cement they need and it's like 2.3658987 and eventually they're told, let's just take four. Everything is four. Always extra buffers.
\end{abstract}

Banks were left frustrated, not seeing the point of collecting all these granular bankspecific data. This can be understood by using the work of Power and others (Boswell, 2008; Gorur, 2015; Kelley and Simmons, 2015; Mahmood et al., 2019; Power, 1997), who have described performance measures and infor-mation as playing a symbolic role: they are valued as a means of signalling order and control. In his work on audits, Power (1997, 2003) argues that they operate as 'rituals of verification', providing assurances where there are low levels of trust. 
Just signalling that banks have to collect all these granular data and compute elaborate models substantiates the claim that supervisors are digging deep, and being thorough. The pan-European stress tests symbolised a shift from 'biased' and 'weak' national supervision, to 'impartial' and 'rigorous' European supervision.

Besides a message of rigour, the simplicity of the exercise also worked to its advantage. The stress test can basically be presented as a ranking of banks in a crisis situation, making it easy to explain and disseminate to a wider public. This raised awareness that European supervisors were 'taking control', they were mea-suring banks' health and setting clear capital goals. ${ }^{3}$ This added value of the stress test was picked up by respondents as well. During an interview, a respon-dent confessed:

It's a very visible exercise. It helps to explain to people what it is I do. They've heard about it, seen it in the news. It gets more attention from a wider public. This is not just in De Tijd [a financial newspaper], it's even on Het Journaal [the daily evening news].

The stress test is a very visible performance measure that is also expected to con-tribute to awareness and trust from wider publics. One particularly important public is found in the financial markets. The reassurance of financial markets cannot be underestimated as an objective of the stress test. The stress test was also expected to send a signal of trust to the markets. As a respondent at the ECB elaborated:

People say they're frustrated with the results; they say they're not credible because they're low. Now there are two reasons for that. One is technical: with a bottom-up stress test, you're going to get downwards-biased results. The other - and people underestimate this - is that you can't see stress testing in isolation. If you look at what happened after the crisis in the US, the FED committed to endless liquidity, and the government committed to a floor under the economy within weeks. And then they said to the banks 'we're going to do a tough stress test'. And if you're a bank asking for 20 billion dollars and they see you're operating mostly in a country where there is a serious commitment not to let the economy slip away, and liquidity risk is non-existent, it's an interesting business proposition. While in Europe, the ECB was cau-tious, for good reason, and governments retreated because they had maxed out on expenditures, and anyway the fiscal stance is more conservative, and then we stressed the banks. Imagine a bank going to the markets and asking 20 billion euro. So, it's obvious that the results were mild. This is not because the people that do this are incompetent, or captured by banks, or intellectually weak or whatever. It would have been irresponsible to come out with a capital request of 100 billion in such a situation.

The performative character of the stress test is important in this regard. By saying that banks were doing fine, markets treated banks as such, ${ }^{4}$ buying the banks time 
to deal with their problems. Signalling trust in an organisation can be key to allowing that organisation to improve their performance outcomes.

To be sure, just saying that banks are healthy in the stress test is not enough; it needs to be a credible statement. In the early 2009 exercises, banks scored well and faltered shortly after. In order to remain a credible exercise, regulators had to make sure that behind the scenes, banks were cleaning up shop. The stress-testing exercises conducted by the ECB and EBA contributed to this in a rather unexpected way. We elaborate on this in the next section.

\section{More than just a ritual: governmentality}

As mentioned, banks are required to fill out extensive templates with over 20,000 granular data points, over several risk categories. To do so, banks need to access granular data from all subsidiary branches in a short amount of time, be able to reconcile data from different risk departments and explain in excruciating detail how various macroeconomic variables will affect their assets. This did not merely serve the ritualistic or symbolic purposes stated earlier. Rather, it also, and more importantly, encouraged banks to improve their selfregulation. A respondent in a bank explained, for instance, how chief executive officers (CEOs) approved higher budgets for risk departments to improve their IT systems in order to successfully complete the stress test. These improvements in the IT systems are then used beyond the stress test to improve banks' day-to-day risk management. Better IT systems help banks complete the stress test faster, but they also help banks detect problems and risks faster in their day-to-day business. Another improvement along these lines is that the stress test brought people together over different departments. A stresstest coordinator in a bank said:

It's a good experience to have, also for our internal stress tests. Because it's so intensive, you really need to go over everything, line by line. And you're also sitting at the table with so many people. That is also very important, this interaction between the different groups. Because when we do internal stress tests, it's not as thorough, and we're not sitting at the table with so many people. Here, it's an important and rich exchange of thoughts and methods that is very valuable to think about stress testing in general.

This testimony shows how the EU-wide stress test facilitated communication between different risk departments, as well as between risk workers and front-line workers in banks. These communication lines remained after the stress test was completed, again improving banks' internal risk management. This then improves overall risk management and performance outcomes.

Theoretically, we tie this to Foucault's (2011) notion of governmentality, used to describe power that is exercised not by directly regulating behaviour, but by steering how individuals or organisations self-regulate. In this concept, Foucault brings together the notion of governing (governer) with modes of thought (menta-lite'). The government does not explicitly act upon an organisation; rather, the 
organisation acts upon itself. As such, the term is often described as the 'conduct of conduct', the state-steering of self-regulation (Lemke, 2011). This emphasis on selfregulation can be seen as characteristic of the transition from liberalism to neo-liberalism; as Renou (2017) observes, the apparent withdrawal of the state actually marks a new kind of interventionism. Individuals and organisations are encour-aged to take responsibility for themselves. Performance indicators typically act as tools of governmentality manifestly by using performance information to make certain outcomes desirable (as demonstrated in Renou's work). However, we addi-tionally find that performance indicators act as tools of governmentality by making certain practices and behaviours desirable and even necessary. While organisations can often readily game outcomes, gaming actual behaviour is much more of a challenge.

To be sure, the latent power exercised by the EBA and ECB is not against the interests of banks. Foucault is adamant that coercion is not necessarily bad. Moreover, this coercion does not mean that organisations are stripped of all their liberties and act as brainwashed 'puppets'. On the contrary, power, as it is discussed by Foucault, can result in an 'empowerment' or 'responsibilisation' of subjects with agency capacities (Bevir, 2010; Lemke, 2011). This empowerment and 'responsibili-sation' is noted in the stress test as well. Supervisors do not simply hand banks knowledge about what is healthy or risky. The EBA's common methodology includes predefined categories, but banks still have the room to object or disagree (at least in theory). They are encouraged to think for themselves. Banks picked up on the learn-ing experience that they had through the stress test. ${ }^{5}$ As a risk director noted:

We read papers and we follow workshops and we try to keep up, but it's not always easy to find time. The stress test forced us to look at things that we had been neglect-ing. So, it's a good learning experience. It's a new kind of learning, not just from books, but learning as you go.

At first sight, it seems that the stress test just assesses banks' performance in a stress scenario, and penalises accordingly. Banks that see a big drop in their capital ratios need to recapitalise or de-risk their portfolio. However, there is more going on. The stress test not only passively maps which banks perform well, but also actively shapes this performance. The stress test is a tool of governmentality that coerces banks to act upon themselves, and improve performance outcomes, merely by calculating the performance indicator. The stress test is thus latently constitu-tive of the performances it measures.

\section{Conclusion: the latent functions that make performance indicators persist}

Over the past decade, stress testing has become part and parcel of banking regu-lation in the EU. The EU-wide stress test calculates how banks would fare in a 
hypothetically plausible yet adverse stress scenario. Many comparable indicator regimes in national and international governance have been criticised for generat-ing dysfunctional effects. On a theoretical level, we therefore asked under which conditions performance indicators, such as the stress test, can improve perfor-mance outcomes, despite their proven weaknesses and dysfunctions. The manifest objective of performance indicators is to measure performance so as to use this information for learning, steering and control, or accountability (Van Dooren et al., 2015). Besides these manifest functions and the oftenaccompanying dys-functions, we argue that indicators fulfil important latent functions as well, which have been largely overlooked so far. Based on interviews with stress-testing teams in Belgian banks and the NBB, and consultants and officials at the EBA and ECB, this article took a closer look at the latent functions of performance indicators, and how they can contribute to performance outcomes.

First of all, we found that what is commonly seen as a dysfunction of a perfor-mance indicator need not negatively affect performance outcomes. Like many other indicators, stress tests seem to face validity issues. These seem to challenge the manifest goals of performance indicators, that is, accurately measuring perfor-mance in order to steer performance outcomes (Van Dooren et al., 2015). However, dysfunctions such as inaccurate measurement can serve an important role in furthering the overall objective of improving performance outcomes. Compromising on accuracy proved to be a necessary part of a trade-off to ensure a level playing field, which was key to the overall credibility and legitimacy of the stress test, allowing it to improve performance outcomes.

Second, our fieldwork corroborates and complements earlier findings in the literature that indicators fulfil important ritualistic functions (Boswell, 2008, 2015; Power, 1997). They can signal that governments are dealing with a problem thoroughly, and that accountability mechanisms are in place, instilling trust. In this article, we showed that these latent functions can also be key to actually improving performance outcomes, a quality that is often overlooked. By stating that an organisation is performing well, and that regulators are on top of the situation, organisations are given the necessary room to actually work on improv-ing performance outcomes. This mechanism is known as performativity (MacKenzie, 2006). As such, these ritualistic functions of performance indicators should not be brushed off as a pleasant side-effect of performance indicators; rather, they should be more widely recognised as key factors in allowing organ-isations to improve performance outcomes.

Finally, we showed that the process of calculating a performance indicator can latently improve performance outcomes in itself. Calculating the stress test inad-vertently caused banks to professionalise their risk departments, which improved banks' internal risk management, in its turn, improving long-term performance outcomes. We explain this mechanism by drawing on Foucault's theory of gov-ernmentality (Foucault et al., 1991): regulators improved performance outcomes by operating on a latent level, by educating and configuring habits, aspirations and beliefs. In the process of calculating the performance indicator, banks updated IT 
systems, increased communication across departments and improved internal pro-cesses. Although they initially only made these changes as part of the process of calculating the performance indicator, they ended up actually improving their internal risk management, and thus their performance outcomes. Banks' perfor-mance outcomes are not improved because they learned from the performance information itself; on the contrary, they actually find the performance information to be invalid. Rather, they improved their performance outcomes by revising inter-nal management systems to be able to calculate the performance information. This mechanism has been largely overlooked in the literature so far, warranting more scholarly attention. The process of how the performance indicator is calculated might be a key factor in explaining why performance indicators succeed in some cases and fail in others.

To conclude, the manifest goal of performance indicators is to produce perfor-mance information that can be used to improve performance outcomes by allow-ing organisations to learn from or reflect on this information, or by rewarding and penalising over- and underperformers. However, an increasing number of critical voices show that, in many cases, performance indicators fail to improve perfor-mance outcomes because of dysfunctions such as gaming or manipulation for political power plays (Davis et al., 2012; Dunleavy et al., 2005; Hood and Peters, 2004; Van Dooren et al., 2015; Van Thiel and Leeuw, 2002). The main contribution of this research is that it shows new, latent, ways in which perfor-mance indicators affect performance outcomes. We show how the process of calculating performance indicators, which is often overlooked in the literature, can in itself improve performance outcomes - regardless of the results of the indicator, and their use or validity. Where a key criticism of performance indica-tors is that performance information is often inaccurate, biased or invalid, we thus rebut with the afterthought that using numbers that do not count can latently help to improve performance outcomes.

\section{Funding}

This research was funded by the Research Foundation-Flanders (FWO) through a PhD fellowship grant to the corresponding author, grant number $11 \mathrm{X} 9818 \mathrm{~N}$.

\section{Notes}

1. One in Amsterdam and one in Brussels, with both organised by the Professional Risk Managers' International Association (PRMIA).

2. We had the opportunity to speak to four of our previously interviewed respond-ents informally.

3. The 2014 stress test even included an official hurdle rate of a 5.5\% capital ratio, making it even easier to assess which banks were passing and failing the stress test. 
4. Market credibility, and with it confidence, shifted in Europe after the ECB took over the stress tests (previously ran by the Committee of European Banking Supervisors (CEBS) ). As Anderson (2016: 9) writes in his comprehensive assessment, 'the tests were viewed as informative and credible. Equity prices and credit default swaps spreads moved substan-tially - improving for banks that were found to be healthy'.

5. To be sure, large parts of conducting the stress test are seen as 'ticking boxes'. This has a lot to do with the restrictions in the common methodology. Risk experts in banks fre-quently vented their frustration by explaining meticulously how certain macroeconomic events would affect their assets, only to receive yet another red flag because the end value exceeded a cap or floor.

\section{References}

Anderson RW (2016) Stress Testing and Macroprudential Regulation: A Transatlantic Assessment. London: CEPR Press.

Berten J and Leisering L (2017) Social policy by numbers. How international organisations construct global policy proposals. International Journal of Social Welfare 26(2): 151-167. Bevan G and Hood

C (2006) What's measured is what matters: Targets and gaming in the English public health care system. Public Administration 84(3): 517-538.

Bevir M (2010) Rethinking governmentality: Towards genealogies of governance. European Journal of Social Theory 13(4): 423-441.

Bohte J and Meier KJ (2000) Goal displacement: Assessing the motivation for organizational cheating. Public Administration Review 60(2): 173-182.

Boswell C (2008) The political functions of expert knowledge: Knowledge and legitimation in European Union immigration policy. Journal of European Public Policy 15(4): 471-488.

Boswell C (2015) The double life of targets in public policy: Disciplining and signalling in UK asylum policy. Public Administration 93(2): 490-505.

Bouckaert G and Balk W (1991) Public productivity measurement: Diseases and cures. Public Productivity \& Management Review 15(2): 229.

Boyne GA and Chen AA (2006) Performance targets and public service improvement. Journal of Public Administration Research and Theory 17(3): 455-477.

Braithwaite J (2014) Restorative justice and responsive regulation: The question of evidence. RegNet Research Paper 51: 27.

Cecchetti SG and Schoenholtz KL (2016) Are European stress tests stressful enough? Moneyandbanking.com.

Christensen T and Fan Y (2016) Post-New Public Management: A new administrative paradigm for China? International Review of Administrative Sciences 84(2): 389-404.

Davis KE, Kingsbury B and Merry SE (2012) Indicators as a technology of global gover-nance. Law \& Society Review 46(1): 71-104.

De Vries MS (2010) Performance measurement and the search for best practices. International Review of Administrative Sciences 76(2): 313-330.

Doig A, McIvor S and Theobald R (2006) Numbers, nuances and moving targets: Converging the use of corruption indicators or descriptors in assessing state develop-ment. International Review of Administrative Sciences 72(2): 239-252.

Dowd K (2015) Central bank stress tests: Mad, bad, and dangerous. Cato Journal 35(3): 507-524. Available at: http://dro.dur.ac.uk/23340/ (accessed 13 February 2019).

Drisko J and Maschi T (2015) Content Analysis. Oxford: Oxford University Press. 
Dunleavy P et al. (2005) New Public Management is dead - Long live digital-era gover-nance. Journal of Public Administration Research and Theory 16(3): 467-494.

Elliott L (2016) The EBA's stress tests reveal their own lack of credibility. The Guardian, 1 August. Available at: https://www.theguardian.com/business/economics-blog/2016/ aug/01/ebastress-tests-reveal-their-own-lack-credibility

Foucault M (2011) The Government of Self and Others: Lectures at the College De France, 19821983. Palgrave Macmillan.

Foucault M et al. (1991) The Foucault Effect: Studies in Governmentality: With Two Lectures by and an Interview with Michel Foucault. Chicago, IL: University of Chicago Press.

Gorur R (2015) Producing calculable worlds: Education at a glance. Discourse: Studies in the Cultural Politics of Education 36(4): 578-595.

Hood C and Peters G (2004) The middle aging of New Public Management: Into the age of paradox? Journal of Public Administration Research and Theory 14(3): 267-282.

Hoogenboezem JA (2004) Local government performance indicators in Europe: An exploration. International Review of Administrative Sciences 70(1): 51-64.

Johnston J (2004) Assessing government's performance management capability: the case of the Australian electricity industry. International Review of Administrative Sciences 70(1): 123-136.

Kagan RA (1995) What socio-legal scholars should do when there is too much law to study. Journal of Law and Society 22(1): 140.

Kelley JG and Simmons BA (2015) Politics by number: Indicators as social pressure in international relations. American Journal of Political Science 59(1): 55-70.

Klenk T and Reiter R (2019) Post-New Public Management: Reform ideas and their appli-cation in the field of social services. International Review of Administrative Sciences 85(1): 3-10.

Lemke T (2011) Foucault, Governmentality, and Critique. Colorado, CO: Paradigm Publishers. Levi-Faur D (2005) The global diffusion of regulatory capitalism. The Annals of the American Academy of Political and Social Science 598(1): 12-32.

MacKenzie DA (2006) An Engine, Not a Camera: How Financial Models Shape Markets. MIT Press.

Mahmood M, Weerakkody V and Chen W (2019) The role of information and communi-cations technology in the transformation of government and citizen trust. International Review of Administrative Sciences, doi: 10.1177/0020852318816798

Merton RK (1968) Social Theory and Social Structure. The Free Press.

Mikuła $L$ and Kaczmarek U (2019) From marketization to recentralization: The health-care system reforms in Poland and the post-New Public Management concept. International Review of Administrative Sciences 85(1): 28-44.

Mol NP and De Kruijf JAM (2004) Performance management in Dutch central govern-ment. International Review of Administrative Sciences 70(1): 33-50.

Nielsen PA (2014) Performance management, managerial authority, and public service performance. Journal of Public Administration Research and Theory 24(2): 431-458.

O’Neill O (2002) A Question of Trust. New York, NY: Cambridge University Press.

Pidd M (2005) Perversity in public service performance measurement. International Journal of Productivity and Performance Management 54(5/6): 482-493.

Pires RRC (2011) Beyond the fear of discretion: Flexibility, performance, and accountability in the management of regulatory bureaucracies. Regulation \& Governance 5(1): 43-69. 
Pollitt C (2018) Performance management 40 years on: A review. Some key decisions and consequences. Public Money \& Management 38(3): 167-174.

Pollitt C and Talbot C (2004) Unbundled Government: A Critical Analysis of the Global Trend to Agencies. London: Routledge.

Power M (1997) The Audit Society: Rituals of Verification. Oxford: Oxford University Press. Power M (2003) Auditing and the production of legitimacy. Accounting, Organizations and Society 28(4): 379-394.

Radin BA (2006) Challenging the Performance Movement: Accountability, Complexity, and Democratic Values. Washington DC: Georgetown University Press.

Reiter R and Klenk T (2018) The manifold meanings of 'post-New Public Management' - A systematic literature review. International Review of Administrative Sciences 85(1): 11-27.

Renou Y (2017) Performance indicators and the new governmentality of water utilities in France. International Review of Administrative Sciences 83(2): 378-396.

Sarfaty G (2011) Regulating through numbers: A case study of corporate sustainability reporting. Virginia Journal of International Law 53: 575-624.

Schwartz-Shea P and Yanow D (2012) Interpretive Research Design: Concepts and Processes. Abingdon: Routledge.

Smith P (1995) Performance indicators and outcome in the public sector. Public Money \& Management 15(4): 13-16.

Stone DA (2002) Policy Paradox: The Art of Political Decision Making. New York: Norton. Taylor J (2011) Factors influencing the use of performance information for decision making in Australian state agencies. Public Administration 89(4): 1316-1334.

Termeer CJaM, Dewulf A, Breeman G and Stiller SJ. (2013) Governance capabilities for dealing wisely with wicked problems. Administration \& Society 47(6): 680-710. doi: $10.1177 / 0095399712469195$

Timmermans S and Tavory I (2012) Theory construction in qualitative research. Sociological Theory 30(3): 167-186.

Van Dooren W, Bouckaert G and Halligan J (2015) Performance Management in the Public Sector. London: Routledge.

Van Thiel S and Leeuw FL (2002) The performance paradox in the public sector. Public Performance \& Management Review 25(3): 267-281.

Walker RM, Damanpour F and Devece CA (2011) Management innovation and organiza-tional performance: The mediating effect of performance management. Journal of Public Administration Research and Theory 21(2): 367-386.

Walshe K, Harvey G and Jas P (2010) Connecting Knowledge and Performance in Public Services: From Knowing to Doing. Cambridge: Cambridge University Press.

Yanow D and Schwartz-Shea P (2006) Interpretation and Method: Empirical Research Methods and the Interpretive Turn. Armonk: M.E. Sharpe.

Shirley Kempeneer is a PhD Fellow at the University of Antwerp, Belgium. She is affiliated to the Department of Political Sciences in the Research Group of Politics and Public Governance. Her dissertation deals with transnational regulation through indicators. She focuses on the case of the EU-wide banking stress test to gain an in-depth understanding of the regulatory effects of calculating indicators. 
Wouter Van Dooren is a Professor of Public Administration at the University of Antwerp and the Antwerp Management School, Belgium. He is affiliated to the Department of Political Sciences in the Research Group of Politics and Public Governance. His main research interests are performance measurement and man-agement in the public sector, accountability, participation, and citizen-state interactions. 